\title{
KEITH BUSBY, French in Medieval Ireland, Ireland in Medieval French. The Paradox of Two Worlds
}

\section{G. Matteo Roccati}

\section{OpenEdition}

\section{Journals}

\section{Édition électronique}

URL : http://journals.openedition.org/studifrancesi/14865

DOI : $10.4000 /$ studifrancesi. 14865

ISSN : 2427-5856

\section{Éditeur}

Rosenberg \& Sellier

\section{Édition imprimée}

Date de publication : 1 décembre 2018

Pagination : $472-473$

ISSN : 0039-2944

\section{Référence électronique}

G. Matteo Roccati, « KEITH Busby, French in Medieval Ireland, Ireland in Medieval French. The Paradox of Two Worlds », Studi Francesi [En ligne], 186 (LXII | III) | 2018, mis en ligne le 01 janvier 2019, consulté le 06 janvier 2021. URL : http://journals.openedition.org/studifrancesi/14865 ; DOI : https://doi.org/ 10.4000/studifrancesi. 14865

Ce document a été généré automatiquement le 6 janvier 2021

\section{(c) (i) () $\Theta$}

Studi Francesi è distribuita con Licenza Creative Commons Attribuzione - Non commerciale - Non opere derivate 4.0 Internazionale. 


\title{
KEITH BUSBY, French in Medieval Ireland, Ireland in Medieval French. The Paradox of Two Worlds
}

\author{
G. Matteo Roccati
}

\section{RÉFÉRENCE}

KEITH BUSBY, French in Medieval Ireland, Ireland in Medieval French. The Paradox of Two

Worlds, Turnhout, Brepols, 2017, «Medieval Texts and Cultures of Northern Europe» 27, $516 \mathrm{pp}$.

1 Le livre traite de «the most neglected area of medieval Francophonia» (p. 2), il est organisé en deux parties, dans la première il examine la situation et le rôle de la langue et de la littérature française dans l'Irlande médiévale, dans la seconde la représentation de l'Irlande dans la littérature française médiévale jusqu'au milieu du XIv siècle, le dernier texte pris en compte étant Melyador de Froissart. Le premier chapitre examine les témoignages d'une situation multilingue en Irlande avant et après l'arrivée de colonisateurs normands en provenance de Grande Bretagne (1169): les traces laissées par les conflits à l'intérieur de l'ordre cistercien, dans les œuvres latines de Giraud de Barri et de Roger Bacon et dans les textes littéraires en français, ainsi que dans les chartes ou attestés par les contacts politiques et marchands. Il étudie ensuite (ch. II) les textes littéraires français composés sur le territoire irlandais ( $L a$ geste des Engleis en Yrlande, The Walling of New Ross, deux autres brefs poèmes du ms. Harley 913) et il élargit l'enquête aux manuscrits et aux textes copiés ou ayant circulé en Irlande (le Roman de Horn, l'Histoire de Guillaume le Maréchal, des œuvres relevant de la littérature arthurienne et de la matière antique), aux inscriptions sur les pierres tombales, aux inventaires de bibliothèque et aux témoignages de l'utilisation du français comme langue de culture et de prestige. Dans ce chapitre il est notamment question des traductions du latin par Jofroi de Waterford (Darès le Phrygien, Eutrope, Secretum 
secretorum). Comme celui-ci affirme les avoir réalisées avec la concours de Servais Copale, sans doute son copiste, dont plusieurs documents attestent l'activité de marchand à Waterford, on peut légitimement penser qu'elles ont été menées à leur terme à Waterford même et non à Paris comme on le croyait auparavant.

2 Vient ensuite l'étude de l'évolution de la vision de l'Irlande comme terre de «merveilles»: «its role as a generator of narrative material and its image in the resulting texts and traditions» (p. 2). L'A. prend d'abord en considération (ch. III) les textes latins (Historia Britonum de Nennius, De mirabilibus Hibernie, Topographia Hibernica de Giraud de Barri, Navigatio sancti Brandani, Visio Tnugdali, Tractatus de Purgatorio sancti Patricii, St. Modwenna), et leurs adaptations en langue d'oïl. Il examine ensuite (ch. IV) la connaissance de l'Irlande dans de nombreux textes, notamment Erec et Enide, les lais bretons, Les merveilles de Rigomer, Durmart le Galois, Waldef, Gui de Warewic, Fouke le Fitz Waryn, mais il conclut que «the presentation of Ireland in the romances considered in this chapter is consistently inconsistent» (p. 327). Un dernier chapitre (V) traite des éléments irlandais dans la matière tristanienne et arthurienne avec une attention spéciale pour «the Irish princess theme» (p.329), mis en rapport avec la réalité des mariages politiques mixtes. Le bilan final souligne le fait que, depuis la conquête, tout au long de ces siècles «the isle of marvels provided the necessary otherness in the world of romance» (p.421), l'essor de l'anglais comme langue littéraire amènera en revanche la marginalisation de la culture irlandaise.

3 La bibliographie pp.423-484, l'index des manuscrits pp. 485-486, et le General Index pp.487-514, complètent cet ouvrage dense et riche d'analyses et de données rassemblées ici d'une manière inédite. 